\title{
The Value of Great Customer Service:
}

The Economic Impact For Online Retail and Other Consumer Categories
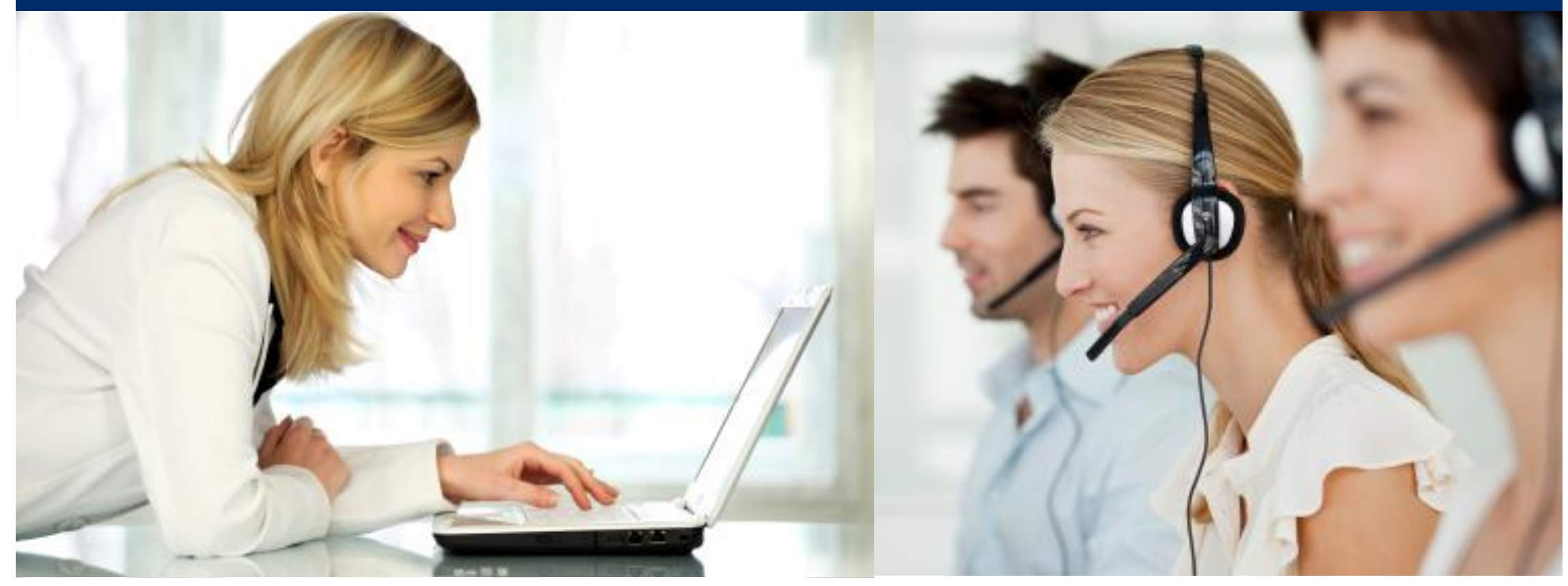

March 2010

Administered by:

Toluna

Including Greenfield Online
Sponsored by:

STELLAService
Developed by:

OVUM 


\section{Survey Background}

In March 2010, STELLAService commissioned a consumer survey to examine the value of great customer service in the U.S. economy, with a particular focus on how great customer service impacts the online retail category. For the purposes of this survey, customer service is defined as the relationship a customer has with a company and its representatives. This includes customer support and communication with representatives via phone, email or Web chat, availability of online tools for finding information, and shipping, delivery and returns.

The survey explored how much - if at all - great customer service impacts the purchasing decisions of consumers. In addition to exploring the extra amount consumers might pay if they know they would receive great service, the survey also aimed to better understand which specific aspects of the customer experience most significantly affect the ways consumers choose one company over another.

The online survey polled 304 U.S. consumers, ages 18 years and older, and asked them a range of questions about their spending habits and opinions of customer service in the online retail category, as well as in many other consumer categories. The other categories included financial services, cable/satellite TV, landline carriers, wireless carriers, Internet service providers, travel and transportation, hotel, government agencies, healthcare, consumer products, insurance, utilities and paid subscriptions.

\section{Specific topics covered in the survey included:}

I. The extra amount (the "premium") consumers are willing to spend on a product or service if they know they will receive great customer service;

II. The customer service factors and considerations that are most important to online consumers when purchasing products over the Internet; and

III. Consumer behavior subsequent to receiving great customer service 


\section{Executive Summary}

Despite the challenging economic environment, consumers are willing to spend an extra $9.7 \%$ for great customer service. Consumers in the online retail category are willing to pay even more $(10.7 \%)$ for great service, which should come as no surprise given the comfort and peace of mind that most consumers want while purchasing from the seemingly distant and remote online marketplace.

Data suggests that consumers have high expectations when it comes to defining great customer service - especially around the availability and responsiveness of customer service representatives (CSRs). Businesses that achieve this high level of customer care are likely to enjoy increases in sales and customer loyalty by triggering repeat purchases and invaluable word-of-mouth promotion.

\section{All Consumer Categories}

Est. value of great customer service per year:

\section{$\$ 267.8$ billion}

Average premium that a consumer is willing to pay for great customer service

$$
9.7 \%
$$

\section{Online Retail}

Est. value of great customer service per year:

\section{$\$ 17.3$ billion}

Average premium that a consumer is willing to pay for great customer service

\section{$10.7 \%$}




\section{Key Findings}

Regardless of the

category, consumers are willing to pay more if it means they will receive great customer service.
The value of great customer service in the U.S. economy is a staggering $\$ 267.8$ billion per year. This figure was calculated based on the average spend per person per year with each type of company. Value is the extra percentage that people are willing to spend if they know they will receive great service.

Results indicate that Internet service providers, hotels, consumer products, online retail and healthcare are the categories with the highest customer service "premium".

\section{Value of Great Customer Service by Category}

\begin{tabular}{lrrr}
\hline Consumer Category & $\begin{array}{r}\text { Avg. spend per } \\
\text { person per year }\end{array}$ & $\begin{array}{r}\text { Avg. extra value } \\
\text { consumers are } \\
\text { prepared to pay }\end{array}$ & $\begin{array}{r}\text { Est. total value of } \\
\text { great customer } \\
\text { service }(\mathbf{\$ m})\end{array}$ \\
\hline Internet service provider & $\$ 649.34$ & $11.2 \%$ & $\$ 17,978$ \\
Hotel & $\$ 546.71$ & $11.0 \%$ & $\$ 14,834$ \\
Consumer products & $\$ 1,361.84$ & $10.9 \%$ & $\$ 36,593$ \\
\hline Online retail & $\$ 653.29$ & $10.7 \%$ & $\$ 17,267$ \\
\hline Healthcare & $\$ 1,047.04$ & $10.6 \%$ & $\$ 27,338$ \\
Wireless carrier & $\$ 854.61$ & $10.2 \%$ & $\$ 21,543$ \\
Insurance & $\$ 1,307.57$ & $9.7 \%$ & $\$ 31,410$ \\
Financial services & $\$ 640.46$ & $9.7 \%$ & $\$ 15,346$ \\
Cable/satellite TV & $\$ 911.84$ & $9.7 \%$ & $\$ 21,815$ \\
Travel and Transportation & $\$ 929.61$ & $9.5 \%$ & $\$ 21,825$ \\
Landline carrier & $\$ 549.67$ & $8.8 \%$ & $\$ 11,922$ \\
Utilities & $\$ 573.87$ & $8.6 \%$ & $\$ 12,251$ \\
Government agencies & $\$ 463.82$ & $7.7 \%$ & $\$ 8,837$ \\
Paid subscriptions & $\$ 472.70$ & $7.6 \%$ & $\mathbf{\$}, 887$ \\
\hline Total & $\mathbf{\$ 1 0 , 9 6 2 . 3 6}$ & $\mathbf{N} \mathbf{A}$ & $\mathbf{\$ 2 6 7 , 8 4 6}$
\end{tabular}

Note: Consumer spending is highest (over USD $\$ 1,000$ per year) in healthcare, consumer products and insurance. As a result, the value of great customer service is estimated to be higher for these categories. 


\section{Key Findings}

For the online retail category, the leading factor in determining great customer service is speed of delivery. The disadvantage of ordering products online is that consumers must wait - sometimes for many days or even weeks - for an item to be delivered. If products are delivered quickly, customers are simply more inclined to buy online. The helpfulness of CSRs and the ease of access to information on a retailer's Web site are also at the top of the list for important elements of service for the online retail category.

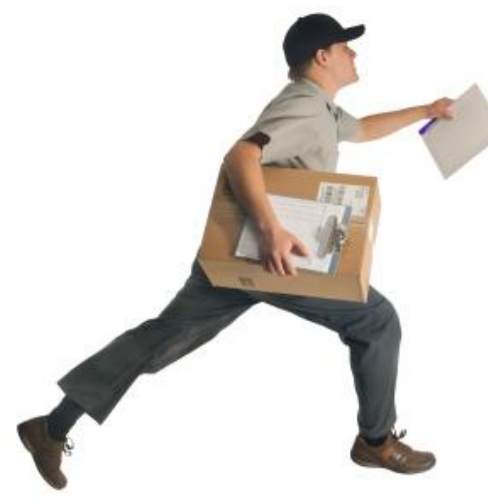

\section{Leading Factors for Great Customer Service}

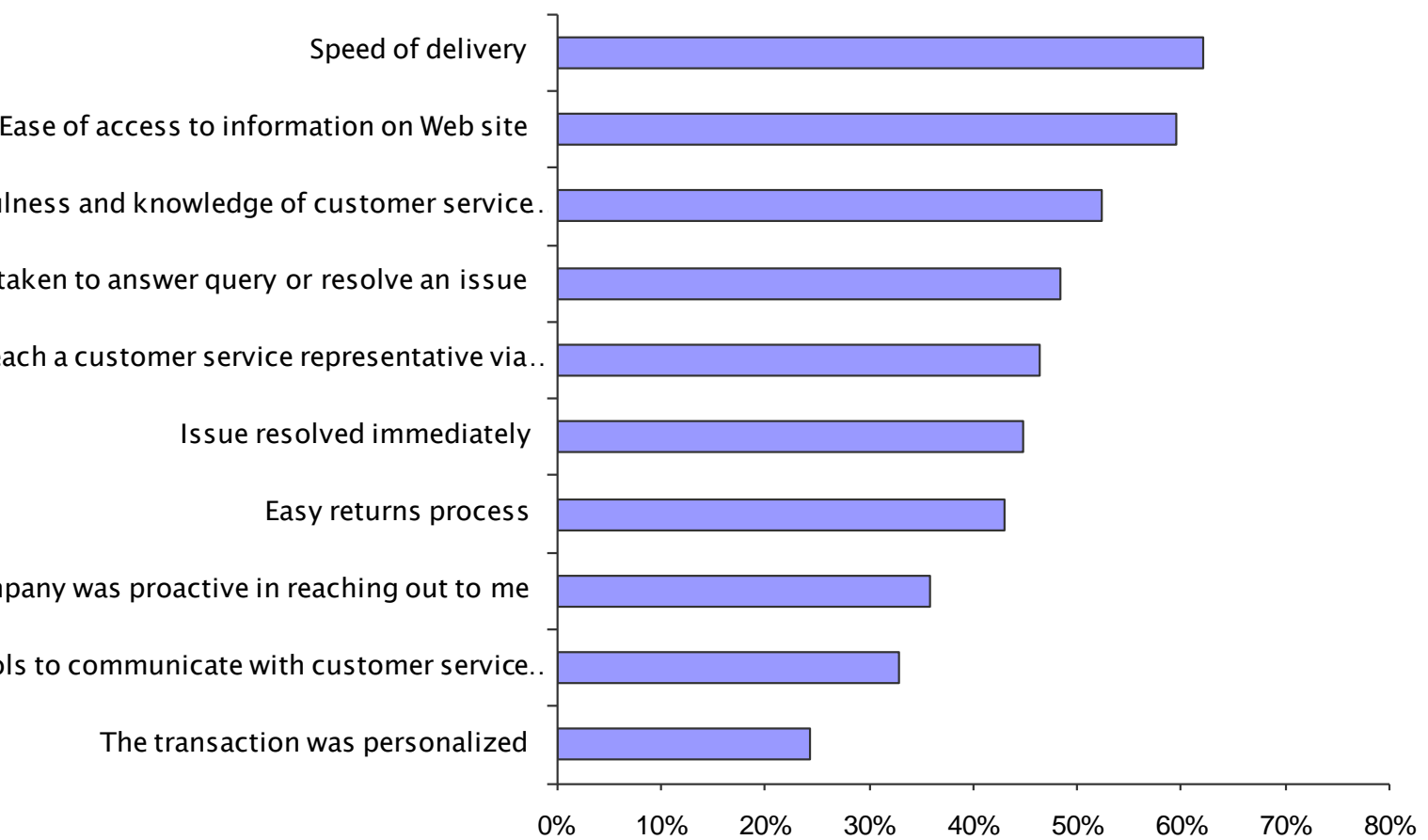

Percentage of respondents 


\section{Key Findings}

While online consumers are willing to spend extra for great service, they maintain high standards for what actually constitutes great customer service.

When

shopping on

sites with

"great

customer

service",

$80 \%$ of

consumers

expect their

emails replied

to within one

hour.

"What is the maximum amount of time you would expect an online retailer with great customer service to keep you on hold before connecting you to a live CSR?"

Data shows that the availability and responsiveness of CSRs is one of the most important elements of a company's customer service proposition. The survey asked consumers about the maximum amount of time they would expect an online retailer with great service to leave them on hold, and over one-third of the respondents stated that companies with "great customer service" should connect their phone calls to a live CSR in less than 30 seconds.

Another question in the survey found that customers also expect speedy email replies from companies that offer "great customer service", with most consumers expecting an email reply within one hour.

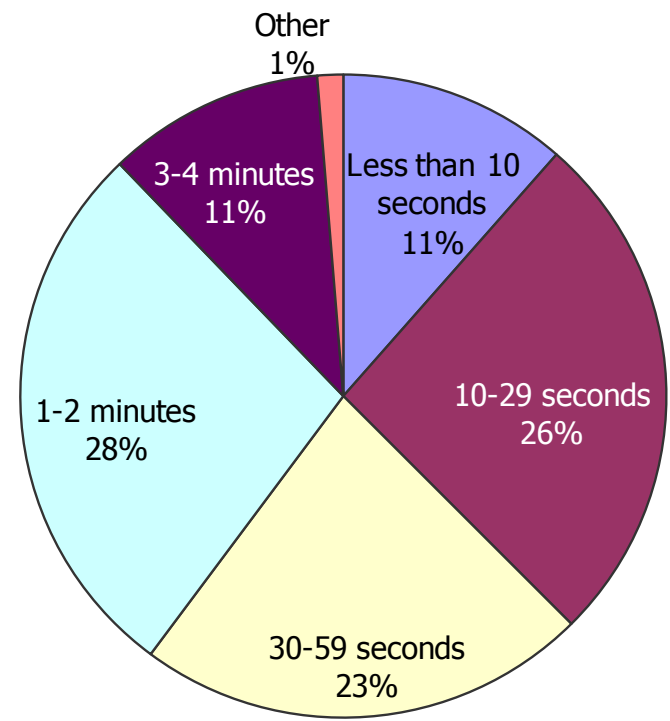




\section{Key Findings}

$70 \%$ of

consumers will use the same

company

again as a

result of

receiving great

customer

service
Although great customer service has been shown to impact spending levels during an individual customer engagement, it also plays a role in increasing customer loyalty. Additionally, $50 \%$ of respondents said that they would make recommendations to family and friends simply as a result of receiving great customer service, and more than $40 \%$ said that they have already purchased a second product from a company due to a previously positive customer experience.

Customer loyalty and word of mouth marketing are other factors that should be considered when calculating the value of great customer service. These behaviors drive additional value by helping companies expand their businesses while minimizing costs for customer acquisition. Therefore, the full value of great customer service is likely to be even higher than the figures presented in this report.

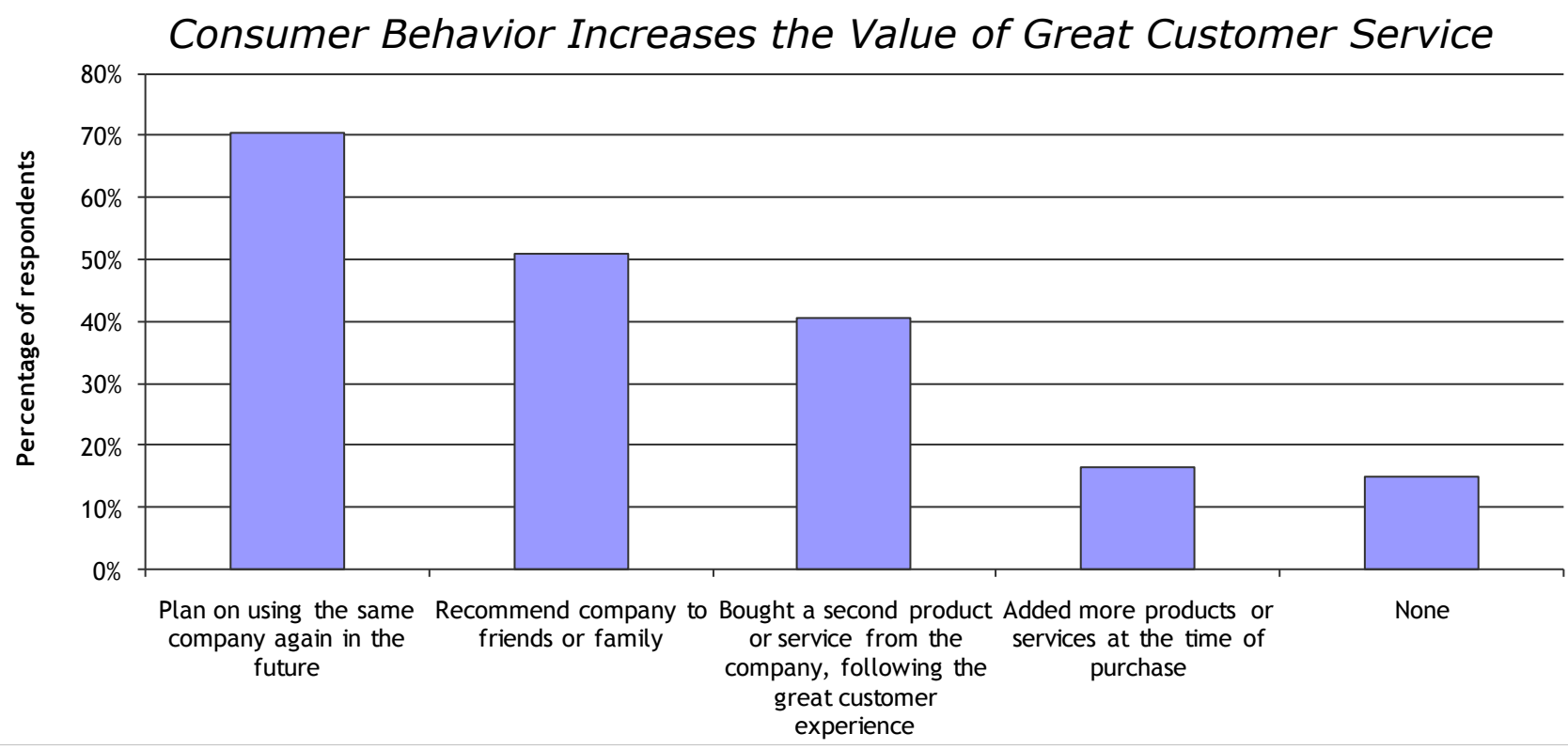

The Value of Great Customer Service: The Economic Impact For Online Retail and Other Consumer Categories 


\section{About the Companies}

\section{Greenfield Online}

Greenfield Online, Inc. provides Internet survey and comparison shopping solutions primarily in North America and Europe. The company provides Internet survey solutions to the marketing research industry. It manages Internet panels, including the Greenfield Online panel in the United States and Canada; and the Ciao panels in Europe, as well as provides solutions in North America via Real-Time Sampling capability that recruits survey takers across the Internet in real time. In addition, Greenfield Online, Inc. offers solutions to aggregate and display information on an array of consumer products, such as consumer electronics, motor vehicles, computers, travel services, and telecommunications. Greenfield Online, Inc. was founded in 1994 and is headquartered in Wilton, Connecticut. More information can be found at: www.greenfieldonline.com

\section{STELLAService}

STELLAService is the first and only company dedicated to publishing objective, in-depth ratings on the customer service performance of online businesses. STELLAService adheres to the highest evaluation standards; it does not inform Internet retailers of the timing of its evaluations and pays for all products purchased from - and returned to - each website it evaluates. Retailers cannot pay to be rated nor can they influence the ratings in any way. The invaluable data obtained by STELLAService is used by consumers to make more informed online purchasing decisions and by companies to obtain crucial business and industry intelligence. Based in New York City, the company's Advisory Council and analysts represent today's thoughtleaders in the area of online customer service. More information can be found at: www.stellaservice.com.

\section{Ovum}

Ovum's primary activity is providing value-added advisory services and consulting to retained and project clients. The company acts as a wellrespected and trusted source of industry data, knowledge and expertise on the commercial impact of technology, regulatory and market changes. Ovum engages in continuous research and industry analysis to determine market dynamics in its specialist sectors. Ovum has developed long-standing relationships with many of its corporate clients, which include major international blue-chip companies such as Alcatel-Lucent, AT\&T, BT, Cable \& Wireless, Cisco Systems, Deutsche Telekom, Fujitsu, HP, IBM, Microsoft, Telstra and Vodafone. Ovum is part of the Datamonitor Group. More information can be found at: www.ovum.com. 